\title{
Smart Energy Meter Management using GSM
}

\author{
Mallikarjun Bhagawati ${ }^{1}$, Vinod Hiremani ${ }^{2}$, Suresh $\mathbf{M}^{3}$ \\ PG-Student, Power and Energy System (EEE Dept), Basaveshwar Engineering College (Autonomous), Bagalkot, \\ Karnataka, India ${ }^{1,2,3}$
}

\begin{abstract}
The present electricity billing system in India is inaccuracy flat and time consuming. Errors get introduced at every stage of energy billing like errors with electro-mechanical meters, human errors while noting down the meter readings and errors while processing the paid bills and the due bills. There is no proper way to know the power usage details, load shedding schedules and power robbery. One of the remedies for these drawbacks is implementation of a Smart energy meter. This paper is on the development of a smart energy meter which is having capabilities like remote monitoring and controlling of energy meter. Here the consumer pays the electricity bill well in advance before the energy consumption which would be entitled as pay first and then use it. Each consumer has varying load demands thus depending on those load demands suitable amount of units $(\mathrm{kWh})$ are recharged based on the pulses from the energy meter, microcontroller decrements the number of units of power consumption and displays the remaining available units on LCD display. When the count becomes zero the load is disconnected and it is reconnected when the consumer recharges the units of power. This system helps the consumers and power distribution companies to access the accurate and updated data from the energy meter by sending a message (SMS) to that energy meter, the information is being sent and received with the help of Global system for mobile communication (GSM) network. This energy meter gives the power cut information to the users with a buzzing sound. It also provides the feature of disconnection of power supply to the load whenever there occurs the power theft activities such as bypassing the power supply, this can be done from the distribution company by sending a message (SMS). This system mitigates the revenue losses of the distribution company a larger extent, which in turn helps distribution company to provide quality power to consumers.
\end{abstract}

Keywords: Energy Meter, Power Supply Unit, transformer Unit, Bridge Rectifier, Voltage Regulator, Microcontroller AT89C51, GSM modem.

\section{INTRODUCTION}

With the growing population of India and its rising electric power needs, the power system has grown rapidly over past 50 years. At present, at the end of every month a person from electricity board goes to every house and take the meter readings manually which are used for electricity bill calculations, this is a sluggish and laborious process. In this conventional billing system people try to manipulate the meter reading by adopting various corrupt practices such as bypassing supply, magnetic interference etc. Thus the conventional billing method is inaccurate, costlier, time consuming and has lack of transparency, hence this is causing a stark amount of revenue loss to the distribution companies. Therefore, several attempts were made to overcome all these drawbacks of conventional billing system. Even though the meters are made digital, the methodology of billing is same. Therefore the scope of this paper is to design and develop a smart energy meter that provides both the suppliers and consumers with user friendly services.

\section{PROBLEM STATEMENT}

With the increasing load demand in power sector, there is a lean revenue collection because of power thefts at consumer premises and also due to non payment of electricity bills. Thus it is necessary to develop a smart energy meter that provides user friendly services.

\section{III.OBJECTIVES}

- To make energy consumption prepaid.

- To centralize the control of all energy meters.

- To prevent power thefts at consumer premises.

- To reduce cost of man power for billing.

\section{BLOCK DIAGRAM}

- In the below block diagram microcontroller, LCD \& the GSM unit is interfaced with the Energy Meter of each house. Every meter has a separate RR number, which is given by the power supplying companies.

- The pulse from energy meter is given to opto-coupler and output of opto-coupler is given to microcontroller.

- The microcontroller continuously decrements the number of units (1 unit= $1 \mathrm{kWh}$ ) as per energy consumption and displays the available units on the LCD attached to the energy meter. 
IJIREEICE

International Journal of Innovative Research in Electrical, Electronics, Instrumentation and Control Engineering

NCAEE 2017

National Conference on Advances in Electrical Engineering NMAM Institute of Technology, Nitte

Vol. 5, Special Issue 2, April 2017

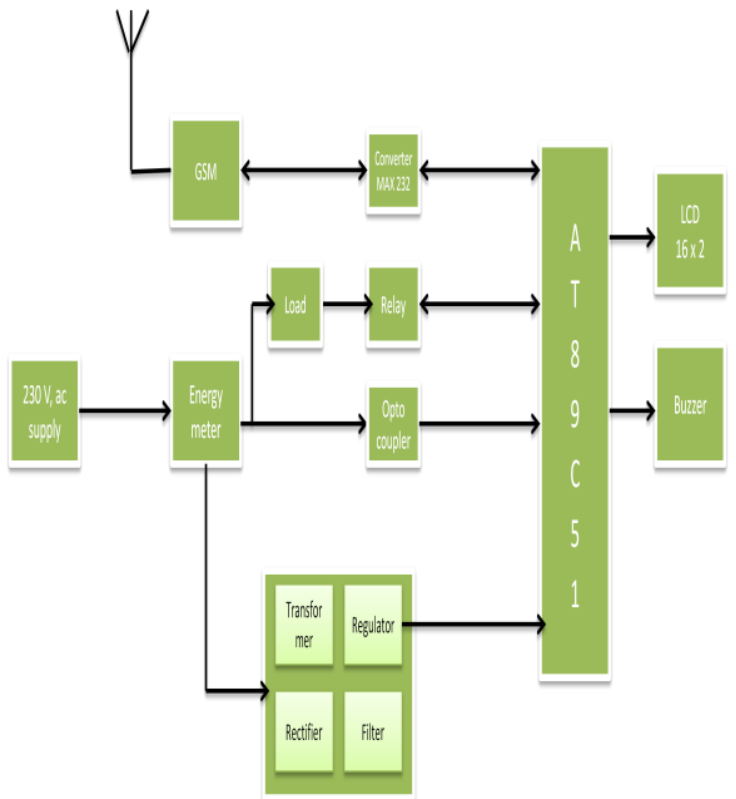

Fig.1: Block Diagram of Smart Energy Meter using GSM

- Output of energy meter is connected to the load through relay. Here relay is used to connect or disconnect the supply to the load.

- When the server (power supplying company) sends request to the GSM modem, the modem commands the microcontroller to perform the required action. The microcontroller in response sends the reply to the modem and the modem in turn sends the data to the server.

- MAX232 is used for data transfer between microcontroller and GSM modem.

\section{A. Main Circuit Diagram}

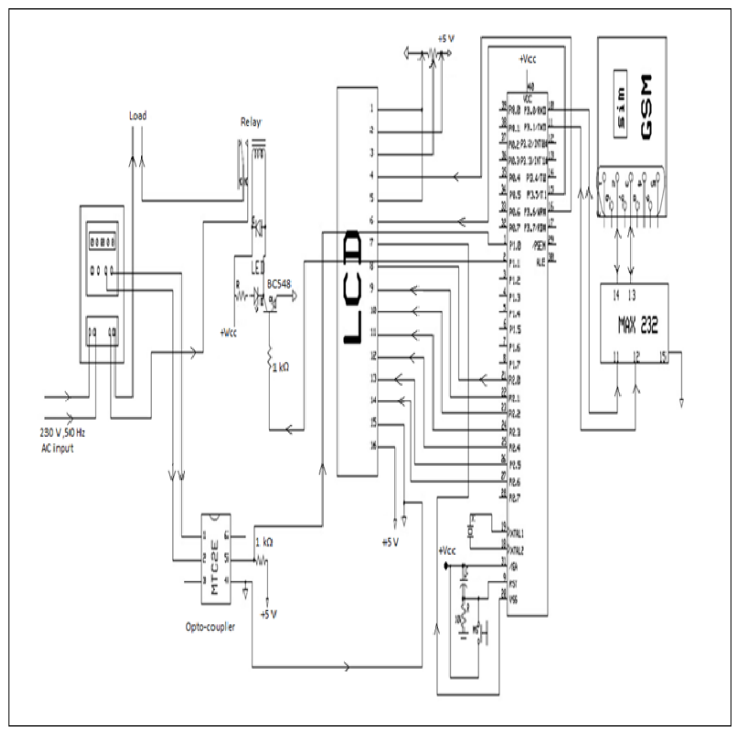

Fig.2: The Main Circuit Connection Diagram
V. FLOW CHART

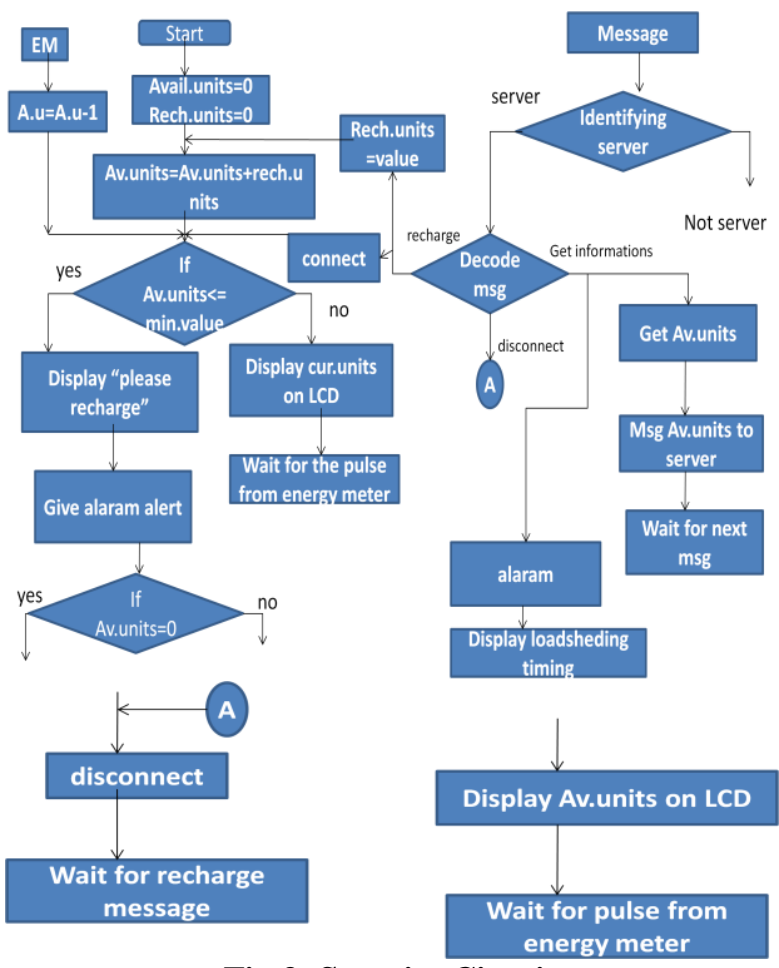

Fig.3: Security Circuit

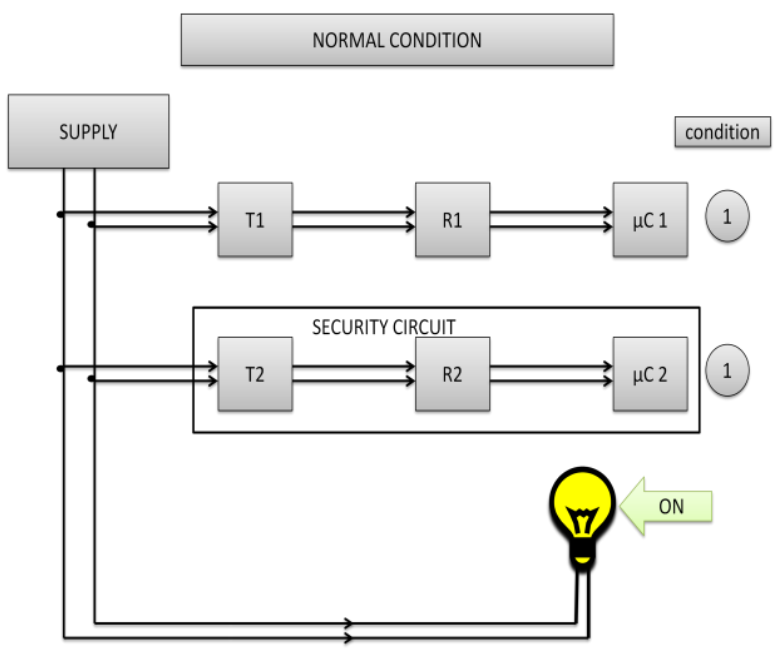

Fig.4: Flow of supply in the circuit

The microcontroller 2 compares the logic level of regulator 1 and 2. If it is 1 and 1 it is normal operation. If the consumer connects supply directly to the load without connecting to energy meter circuit. The main circuit is disconnected where as the security circuit will be still on. Now the microcontroller 2 compares the logic level of regulator 1 and 2. If it is 0 and 1 it informs the GSM to send an SMS to the server that an illegal operation has been performed and the server sends an SMS to GSM modem to immediately disconnect the supply. 


\section{IJIREEICE}

International Journal of Innovative Research in Electrical, Electronics, Instrumentation and Control Engineering

NCAEE 2017

National Conference on Advances in Electrical Engineering NMAM Institute of Technology, Nitte

Vol. 5, Special Issue 2, April 2017

Implementation of security circuit

In this circuit relay is connected to pin 1.7. Logic levels of regulator 1 and 2 are connected to the pin 1.2 and pin 3.3 respectively. These pins are compared by the microcontroller

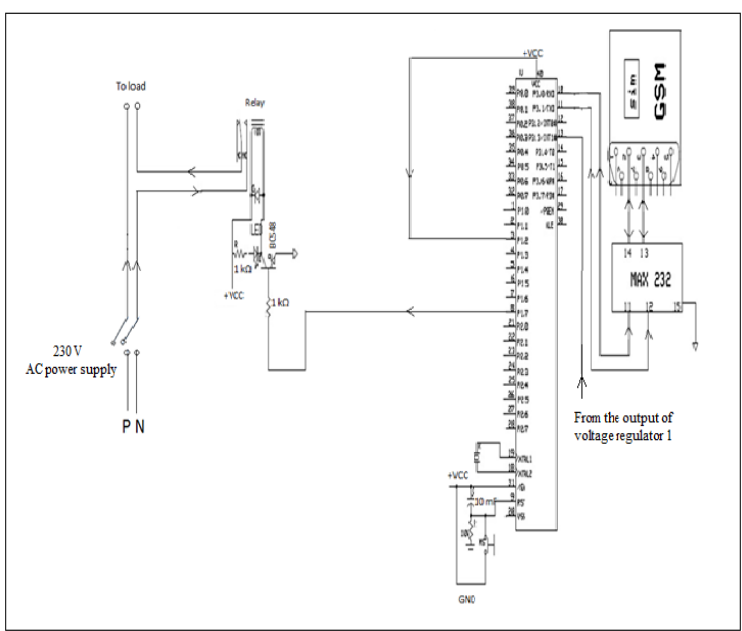

Fig.5: Flow chart for security circuit

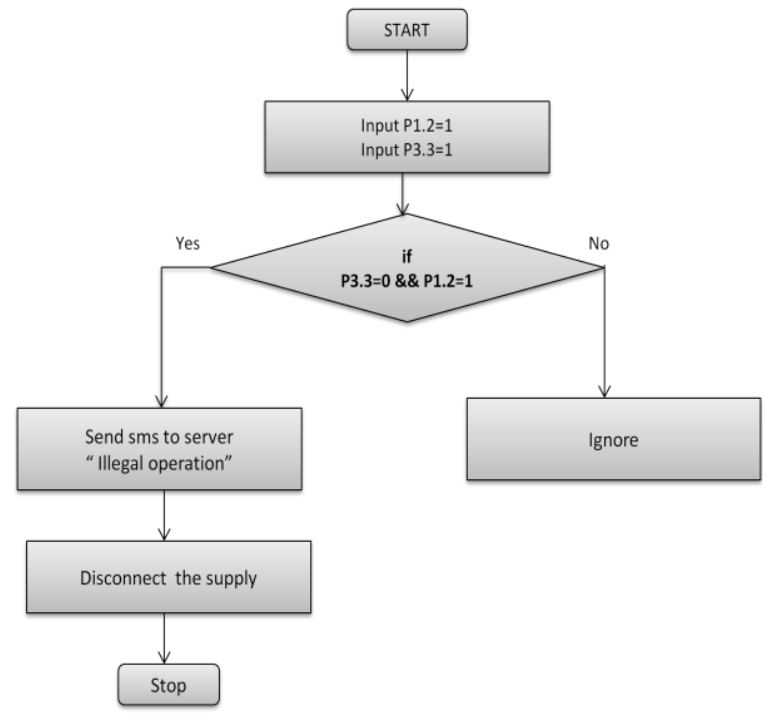

Advantages and Applications

5.1 Advantages

- The whole process of billing can be centralized.

- Cost of manpower for billing / collection is reduced.

- For preventing power theft.

- Avoids non-payment of electricity bills.

- No limit range in network operation because of GSM modem

\subsection{Applications}

- Unit recharge through server (KEB).

- Automatic low unit intimation (MESSAGE) to user.

- Automatic zero unit disconnection to load.
- Status reading like units, RR.No, user name from server (KEB).

- Status reading for user.

- Meter connection/disconnection from server.

- Power theft detection and disconnection in case of bypass supply.

- Displaying load shedding information on LCD with alarm.

Outputs

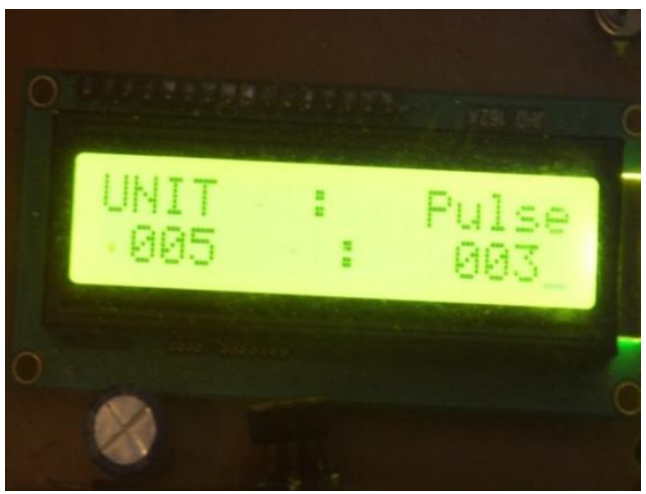

Fig.6: Display of energy meter

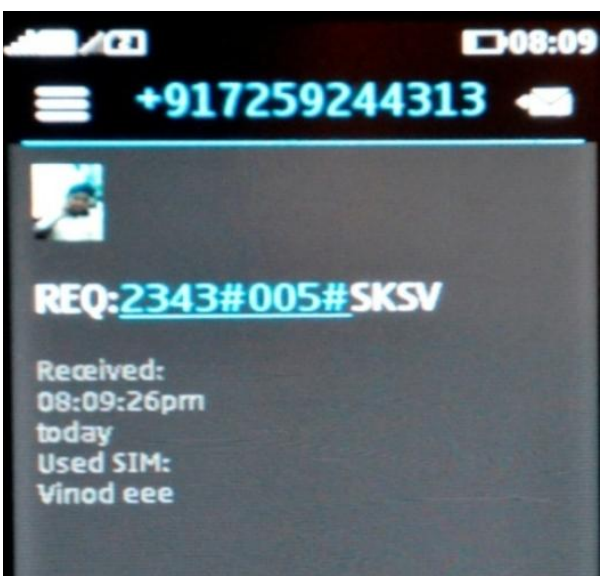

Fig.7: Status reading from server and user.

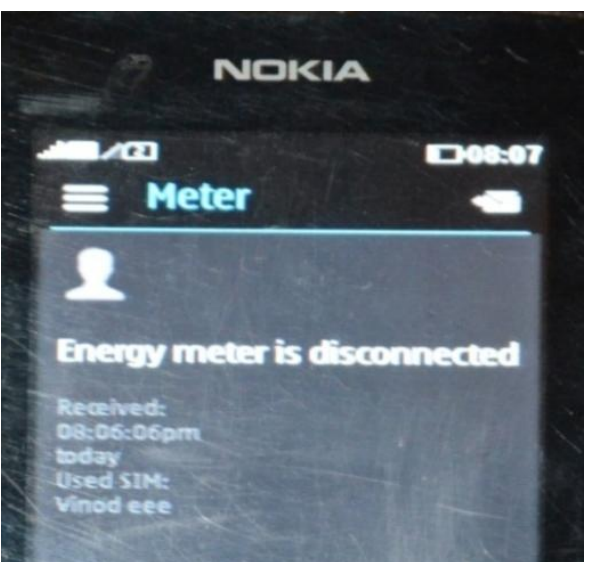

Fig.8: Energy meter disconnection. 
NCAEE 2017

National Conference on Advances in Electrical Engineering NMAM Institute of Technology, Nitte

Vol. 5, Special Issue 2, April 2017

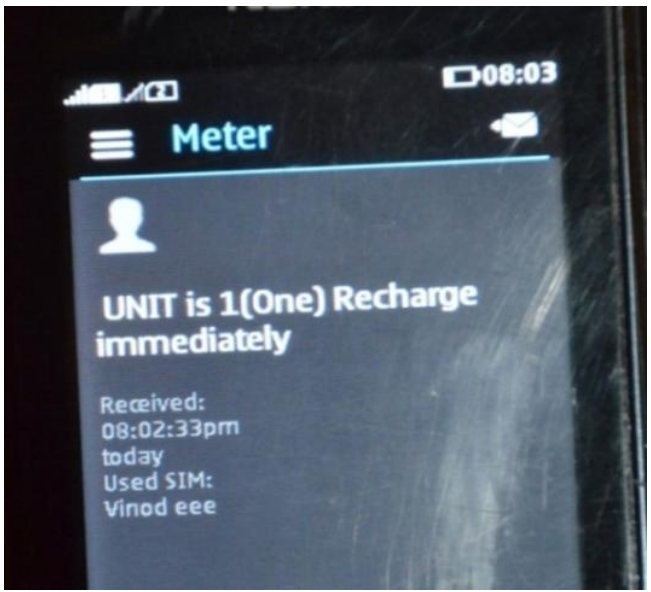

Fig.9: Low unit intimation message to the user.

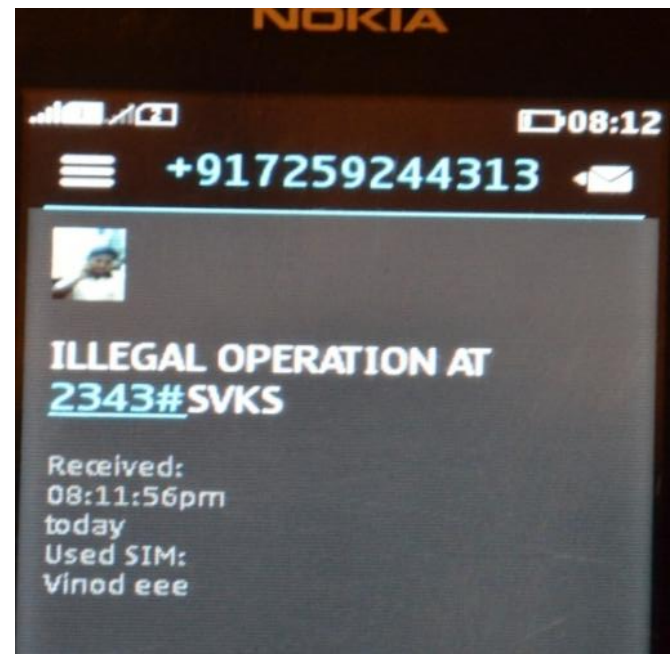

Fig.10: Illegal operation message to server in case of bypassing supply

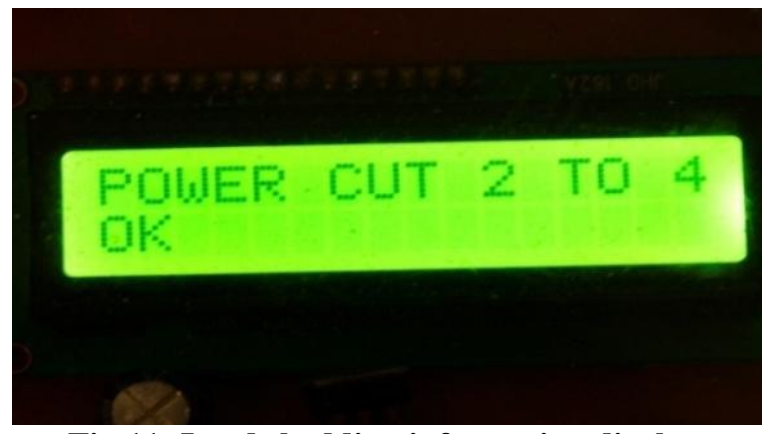

Fig.11: Load shedding information display

\section{CONCLUSION AND FUTURE SCOPE}

\subsection{Conclusion}

By implementation of this project, the metering system is totally enhanced with modern technology. The whole process of operation can be centralized and can be extended to long distances by GSM modem. This project is quite time saving and provides user friendly services.

\subsection{Future scope}

This project can be implemented to the existing energy meter with some modifications like adding the security circuits and using the GSM network for the purpose of centralization of billing system.

\section{AKNOWLEDGEMENT}

The paper is the outcome of guidance, moral support and devotion bestowed on me throughout my work. For this we acknowledge and express my profound sense of gratitude and thanks to everybody who have been a source of inspiration during the training. We wish to express our sense of gratitude to Dr. R. N. Herkal, principal, Basaveshwar Engineering College, Bagalkot. We would like to thank our parents, friends \& well-wishers who have helped me in this report. We would like to extend our thanks to all the staff of Electrical \& Electronics Department of Basaveshwar Engineering College, Bagalkot.

\section{REFERENCES}

[1] Abhinandan Jain, Dilip Kumar and Jyoti Kedi, "Smart and Intelligent GSM based Automatic Meter Reading System", International Journal of Engineering Research and Technology (IJERT), Vol.01.Issue 3, May-2012.

[2] Irafan Quazi, Sachin Kumar Gupta, Rajendra Prasad, "Pre-paid Energy Meter based on AVR Microcontroller", International Journal of Engineering Research and Applications (IJERA). Vol.1, Issue 4, pp.1879-1884.

[3] Abhinandan Jain, Dilip Kumar and Jyoti Kedi," Design and Development of GSM based Energy Meter", International journal of computer applications (0975-888) volume 47-no.12, june-2012.

[4] Mazidi, Muhammad Ali, "8051 Microcontroller and Embedded Systems", 1st edition, prentice hall publications, 1999.

[5] Electrical and Electronics Measurements, 9th edition, J.B.Gupta.

[6] www.engineeringsgarage.com

[7] www.betaengineering.com

[8] www.efy.com

\section{BIOGRAPHIES}

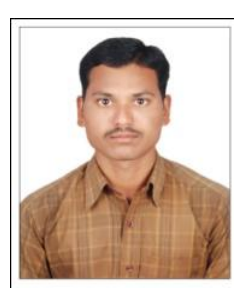

the year 2013.

He was completed M. Tech. degree in power and energy systems at Visvesvaraya Technological University, Belgaum. He is a student member of IEEE and member of Power and Energy Society.

His area of interest is in Power Systems, SCADA, FACTS, Energy Audit and Renewable Energy Systems. 
National Conference on Advances in Electrical Engineering NMAM Institute of Technology, Nitte

Vol. 5, Special Issue 2, April 2017

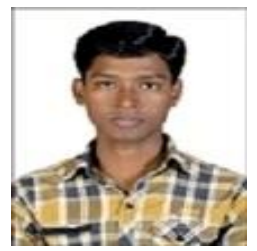

Vinod Hiremani was born in Koppal District, Karnataka; on $5^{\text {th }}$ April 1992.He completed high school, Secondary Education in Gangavathi. He obtained Electrical \& Electronics Engineering degree from Visvesvaraya Technological University, Belgaum in the year 2013. He is currently completed the M. Tech. degree in Power and Energy Systems at Visvesvaraya Technological University, Belgaum. He is a student member of IEEE and member of Power and Energy Society.

His area of interest is in power systems and renewable energy systems.

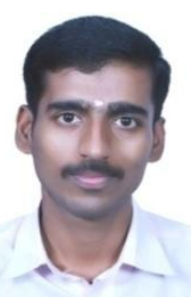

Suresh M was born in Raichur District, Karnataka; on 10th January 1990.He completed high school, Secondary Education in Shakthinagar. He obtained Electrical \& Electronics Engineering degree in SDMIT Ujire, Dist.DK under Visvesvaraya Technological University, Belgaum in the year 2015. He is currently Pursuing the M. Tech. degree in Power and Energy Systems at Visvesvaraya Technological University, Belgaum. He is a student member of IEEE and member of Power and Energy Society.

His area of interest is in Renewable Energy Systems \&Power Systems, 